\title{
Centro Obrero Unión Social en Bogotá (1951-1962) ${ }^{1}$
}

\section{Centro Obrero Unión Social in Bogotá (1951-1962)}

Martín Gil Plata. Pbro. ${ }^{2}$

\section{Resumen}

En este artículo se describen los orígenes de la "Unión Social Centro Obrero", USCO, en Bogotá, la cual, en 2013 cedió sus terrenos y edificaciones a la Fundación Universitaria Monserrate - Unimonserrate. Las acciones iniciales de la USCO se inscriben en las dinámicas del catolicismo colombiano de la década del cincuenta del siglo XX, consignadas en el programa definido por la Conferencia Episcopal en 1945, que determinó, por muchos años, el trabajo social de la Iglesia, sus métodos y perspectivas en relación a los cambios sociales, la actitud frente a la marginación de multitudes, la secularización de la vida cotidiana y la redistribución de los frutos del crecimiento económico.

Palabras clave: Pastoral Social de Iglesia; Mundo obrero; Iglesia. Bienestar.

\begin{abstract}
This article describes the origins of "Unión Social Centro Obrero", USCO, in Bogotá, which, in 2013, gave its land and buildings to Fundacion Universitaria Monserrate. The initial a ctions of USCO a re part of Colombian Catholicism dynamics during in the fifth decade of the twentieth century, included in the program defined by the Episcopal Conference in 1945, which determined, for many years, the social work of the Church, its methods and perspectives in relation to social changes, the attitude towards the marginalization of crowds, the secularization of everyday life and the redistribution of economic growth profits.

Keywords: Church's Social Work; Workers; Church.
\end{abstract} Well-fare. 


\section{Introducción}

La descripción de la obra del COUS, se hace utilizando como fuentes primarias los documentos fundacionales, que están sin editar, centrándose en los folios y registros del COUS entre 1951 y 1962 y como fuentes secundarias, algunos estudios sobre las dinámicas del pensamiento social católico de mediados del siglo XX. Apelar a estas fuentes, implica realizar un ejercicio de hermenéutica, que permita ubicar la creación y arranque del COUS en el contexto de los acontecimientos políticos y económicos de aquellos años.

Los años treinta del siglo XX, estuvieron marcados por el avance de reformas liberales que rompían en buena medida con el orden impuesto por la "hegemonía conservadora" que duró desde 1886, con la constitución de Caro y Núñez, de carácter confesional, y el final del gobierno de Miguel Abadía Méndez en 1930. Entre estas reformas liberales se destacan la expedición de la ley de tierras, la cual daría pie a enfrentamientos armados en el campo, por la posesión y explotación de la tierra, a la continuidad, en forma de guerra de guerrillas, del enfrentamiento entre los dos partidos tradicionales denominado "guerra de los mil días" (1899-1902) y al surgimiento de organizaciones socialistas, como el Partido Socialista Revolucionario, PSR, los cuales adoptaron estrategias de resistencia y lucha por el poder político en Colombia.

Frente a estos eventos, los prelados católicos expresaron decidida oposición, aunque al tiempo reconocían que las situaciones objetivas de injusticia social podrían derivar en la expansión de tales ideas y movimientos reformistas y revolucionarios (Mantilla, 1994: 279-284; Gil, 2006; 122-127). La Iglesia buscó responder a tales situaciones desde su doctrina social, ideando estructuras de trabajo para el naciente mundo obrero y el histórico mundo campesino, que en muchos aspectos replicaban el trabajo de base de los movimientos socialistas como, por ejemplo, el recurso a conferencias, publicaciones periódicas, difusión radiofónica y contacto directo en talleres y fábricas (Cifuentes y Prieto, en Miradas, 2015: 323).

Es así como en 1945, después de múltiples reflexiones y exhortaciones pastorales, la Iglesia colombiana en su conferencia episcopal de aquel año manifestó: "los arzobispos y obispos de Colombia preocupados por el auge del Comunismo en nuestra Patria en los últimos años, que constituye una amenaza para los principios de la civilización cristiana, conmovida ya con la presente conflagración mundial, y ante los graves problemas que se avecinan, determinaron emprender un movimiento social en toda la República para hacer frente común a este inminente peligro y prepararnos a afrontar las difíciles circunstancias que se nos hayan de presentar después de la Segunda guerra mundial, 1939-1945. (La Iglesia, 1945: 179).

Con tal fin, los jerarcas de la Iglesia Católica resolvieron tomar urgentes medidas y al efecto elaboraron un plan para desarrollar de común acuerdo en todas las diócesis las obras de Acción Social como se muestra en la tabla 1: 
Tabla 1. Plan de Trabajo Acción Social de La Iglesia

\begin{tabular}{|c|c|c|c|}
\hline Etapa & Actor & Actividad Y Destinatario & Metodología \\
\hline & Sacerdotes & $\begin{array}{l}\text { Semanas de estudios. } \\
\text { Reuniones de los párrocos. } \\
\text { Curso práctico de acción social en el } \\
\text { Seminario. }\end{array}$ & \\
\hline Preparación & Dirigentes laicos & $\begin{array}{c}\text { Cursos de formación para campesinos. } \\
\text { Cursos de formación en Bogotá para } \\
\text { obreros. }\end{array}$ & $\begin{array}{l}\text { Por medio de la difusión de la doctrina social de } \\
\text { la lglesia: catequesis, sermones, conferencias con } \\
\text { los capitalistas, periódicos (justicia social), hojas } \\
\text { parroquiales, folletos prácticos, radio, altoparlantes, } \\
\text { por medio de la intensificación de la vida cristiana } \\
\text { en el hogar, la escuela, el taller, la fábrica o el } \\
\text { trabajo del campo, orientándola a la vez hacia } \\
\text { un fin social. congregaciones piadosas, ejercicios } \\
\text { espirituales y misiones. } \\
\text { Por medio de una especial formación de la niñez } \\
\text { y la juventud: fundación de escuelas y talleres } \\
\text { parroquiales (ojalá con su granja agrícola), de } \\
\text { oratorios festivos, conferencias sociales en los } \\
\text { principales colegios ya existentes. }\end{array}$ \\
\hline Realizaciones & & $\begin{array}{l}\text { Conservar y perfeccionar las obras de } \\
\text { carácter social existentes. } \\
\text { Crear nuevas organizaciones, } \\
\text { según convenga a las circunstancias } \\
\text { especiales de cada lugar prefiriendo: } \\
\text { asociaciones campesinas, } \\
\text { círculos obreros y granjas agrícolas }\end{array}$ & \\
\hline
\end{tabular}

Fuente: elaborada por el autor con base en (La Iglesia, 1945, p. 81 ).

Esta disposición de trabajo social y doctrinario de la Iglesia Católica colombiana, coincidió con la llegada al país de congregaciones que tenían prolongada trayectoria de trabajo social en el mundo obrero, en particular las Damas Catequistas, fundadas por la beata, Dolores Sopeña, en 1901, en España, congregación reconocida el 21 de noviembre de 1907 por el Papa Pío X como respuesta a la descristianización y miseria material de los trabajadores y sus familias (Londoño, 2004, pp.191-214) (Fernández, 1995, pp. 219-226). En 1946, las Damas Catequistas abrieron en Bogotá cuatro centros de Instrucción: dos en el barrio La Perseverancia: un centro obrero con 300 asistidos y un centro de mujeres con 200 participantes y dos en Barrios Unidos: uno con 515 obreros y otro, abierto en 1948, con 315 obreras.

Entre los primeros miembros del Instituto de Damas Catequistas que llegan a Colombia en 1945, figuran Bertha García-Huidobro, nacida en Santiago de Chile el 19 de marzo de 1897 y fallecida en Bogotá el 17 de marzo de 1976 y María del Pilar García García, española, nacida en Santa Cruz del Retamar, provincia de Toledo, el 27 de septiembre de 1921, quien aún vive. García-Huidobro trabajó 18 años en España, 2 en Italia y 7 en Argentina, antes de venir al país y García García lo hizo en Cuba durante un año hasta 1949.

Los hechos trágicos del 9 de abril de 1948, considerados en muchos sectores de opinión como un intento de golpe del comunismo colombiano, aceleraron el trabajo de muchas de estas instituciones 
y la fundación de muchas otras que atendieran las consecuencias de la violencia desatada en casi todo el territorio nacional entre 1948 y 1953, cuando se iniciaron estrategias de pacificación lideradas por el gobierno nacional en cabeza del general Gustavo Rojas Pinilla, quien llegó al poder mediante un golpe de Estado.

En especial, estas entidades de trabajo social y adoctrinamiento católico, atendían la población en términos de asistencia humanitaria inmediata, en particular mediante obras educativas para huérfanos, alivio a la miseria de los desplazados y atención sanitaria básica en varios centros parroquiales. Su finalidad en síntesis es instructiva, contribuir a aliviar la pobreza, moralizar y fomentar la religión. En cuanto a lo administrativo, la participación del nivel superior en las actividades del Centro Obrero no tiene por sí misma injerencia administrativa o decisiva. La Obra funciona, esencialmente, de la mano de las Damas Catequistas, que determinan las actividades, los grupos y su distribución y los alcances de la formación misma, así:

- Señoras y señores de clase media y alta: acompañan visitas a hogares en pobreza, realizan otras obras de misericordia y cooperan con la exposición de la doctrina espiritual y social de la Iglesia, bajo la guía y autoridad de las Damas Catequistas.

- Jóvenes obreros de uno y otro sexo, sin preparación alguna e incluso analfabetas. Asisten a clases de economía doméstica y formación para empleos secundarios y catequesis.

Según tal esquema, unidireccional, las clases no se oponen (tesis marxista), sino que se pueden auxiliar mutuamente. Las semanas de estudio que se proponen a partir de 1946, tienen carácter introductorio a los graves problemas sociales y consolidan un modo de proceder solidario entre las diver- sas entidades eclesiásticas sin por ello establecer el hábito de reflexión sobre las causas estructurales e históricas de la migración a las ciudades de miles de campesinos. (Mantilla, 1994, p. 282).

En 1950, estas dos religiosas deciden separarse del Instituto porque éste había ido optando por: normas cada vez más estrechas hacia una vida claustral, que el apostolado queda sujeto a trabas que impide el trabajo efectivo, se restringen los días para el trabajo (solo tres días a la semana), y el horario es tan limitado, que se gasta la mitad del tiempo en el viaje a las barriadas obreras y mil limitaciones más de todo orden, de manera que casi el trabajo entre los obreros viene a hacerse accesorio. Se mira como pérdida de tiempo el empleado en el esparcimiento de los obreros, como los deportes y las pequeñas fiestas. (Archivo de Unión Social, fol.4)

Así, en la búsqueda de un marco apostólico más amplio, las religiosas crean un ente autónomo pero idéntico en su intención fundacional al de las Damas Catequistas, llamado las Damas Unión Social, a las cuales se unirían en años posteriores, Rosario Garzón Pinzón, nacida en Villapinzón (Cundinamarca), el 10 de enero de 1938 y fallecida en Bogotá el 1 de enero de 1993 y Bárbara González Salinas, quien aún vive.

\section{Nace la Unión Social Centro Obrero - USCO}

Para empezar este acápite es bueno aclarar que la descripción de algunos hechos sucedidos entre el momento de la fundación de la USCO en 1951 y 1962, se hace con los archivos de esta institución, pues a partir de 1962, no aparecen registros en los documentos originales ni en otras publicaciones conocidas hasta el momento, lo cual presumimos, obedeció, a que, a partir de 1962, los archivos fue- 
ron desechados o simplemente no tuvieron un registro tan riguroso como los citados.

El 13 de mayo de 1951 se fundó la Unión Social Centro Obrero - USCO, autorizada por el Arzobispo Crisanto Luque y con reconocimiento jurídico del Ministerio de Justicia, mediante resolución 11 del 22 de febrero de 1952 y la personería eclesiástica llegó por decreto 111 del 2 de agosto de 1961. USCO se define como una Asociación cuyo objeto es "unir las clases sociales (respuesta alternativa de la Iglesia a la lucha de clases), de tal forma que las gentes acomodadas cumplan sus deberes con las menos favorecidas y éstas no vean en las clases altas sus naturales enemigos" (Archivo, fol. 13).

Se dijo además que esta Asociación jamás perseguiría

Fin político alguno, sino solo la mayor gloria de Dios y moralizar a la clase obrera. Se establecerán Centros de Instrucción para la clase trabajadora en los que enseñarán señoras y señoritas de la Sociedad y donde hubiera facilidades, se les pondrían cajas de ahorro y cooperativas y escuelas gratuitas para sus hijos, y talleres de chicas jóvenes. (Archivo, fol. 21)

En un principio, la obra de la Unión Social se propuso como una presencia en varios ambientes, incluso con cierto carácter misional: Procúrese siempre dentro de la unión de los miembros que las casas tengan vida propia e independiente. Y lo que den impulsados por la caridad sea para los habitantes de la misma población, excepto cuando se trate de Misiones, en que se puede pedir limosnas para promoverlas en otras partes. Al llegar a una población para fundar dicha Asociación, lo primero que harán será ir a pedir la bendición y permiso del prelado o autoridad eclesiástica y visitar a las autoridades civiles. Enseguida se proporcionarán una lista de todas las señoras principales de la población, y las visitarán, reuniéndolas para organizar los primeros trabajos. Empezarán la propaganda de los obreros, avisándoles en sus casas y fábricas para que vayan al Centro (Archivo, fol. 20). Modo de obrar de las Damas Catequistas de Dolores Sopeña, ya desde los primeros años de su fundación (Fernández, 1995, pp. 85-88). A pesar de la dimisión de las dos religiosas en 1951, las estrategias, los lugares y el apostolado propio permanecen invariables en la nueva obra.

En consonancia con los planes de Acción Social Arquidiocesana, USCO propone:

Establecer Centros de Enseñanza para las clases obreras, dirigidas y atendidas por las clases altas, con el fin de instruirlas en sus deberes para con Dios, la Patria y la Sociedad al mismo tiempo que se les brinda ayuda moral, intelectual y material de acuerdo con sus necesidades, visitando sus hogares para curar sus males físicos y morales y llevando una estadística lo más perfecta posible para que los servicios sean más efectivos y mejor su funcionamiento.

Este elemento estadístico, se convertirá en insistencia permanente en toda la vida de la Obra. (Archivo, fol. 13).

En los documentos fundacionales (Archivo, fol. 4) aparecen consignadas las siguientes líneas generales:

a. Formación espiritual seria y profunda, y buena orientación social mediante estudios apropiados, de manera que cada una se sepa conducir conforme a su vocación y resolver las dificultades ordinarias que se le presenten.

b. Dejar campo para que se desarrollen las buenas cualidades e iniciativas particulares para Gloria de Dios.

c. Gran espíritu de unión con la Jerarquía y cooperación y servicio con todas las demás 
obras apostólicas de la Iglesia, especialmente las sociales.

d. Tipo de trabajo amplio y flexible para adaptarse a los diversos medios obreros de las diferentes naciones, dentro de un mismo espíritu de apostolado social.

e. Amplitud respecto del número y clase de obras que deban emprender para atraer al obrero del campo comunista al católico, y sostener al obrero cristiano en su recta orientación.

f. Cierta amplitud de criterio para encauzar la buena voluntad de muchas jóvenes y señoras cristianas hacia un trabajo fructuoso a favor del obrero. El medio colombiano sería el más apto para desarrollar una obra así, dada la disposición de los obreros y la buena voluntad de las otras clases sociales. En Colombia y Latinoamérica aún no se ha perdido el obrerismo de las ciudades para la Iglesia, pero urge un trabajo bien encaminado para impedirlo.

En estas líneas es evidente la subordinación del trabajo social a la evangelización o, mejor aún, a la prevención frente al socialismo y la recuperación de espacios de cristiandad perdidos (Roux, 1983, pp.135-141). De hecho, un elemento indispensable en el contacto con el mundo obrero será la catequesis y la sacramentalización. Para la época, el trabajo social tiene un vínculo indisoluble con la aceptación de la doctrina de la Iglesia y la conformación con sus cánones morales.

Como anécdota, establece uno de los esbozos primeros de la Obra: Las Conferencias se celebrarán generalmente en el mismo local del Centro (...) y se celebra una Misa por sus difuntos el último día, para que así puedan cumplir con el precepto pascual. Hay que avisar con tiempo a los confesores y en número suficiente. Si se les obsequia con algún objeto piadoso o desayuno, sea a todos en general, sin hacer diferencias entre los que comulguen o no. No se obligará a ninguno a recibir los Sacramentos, ni se les rebajará el premio por no haberlos recibido, aunque sí se tendrá en cuenta la asistencia a las Conferencias espirituales para aumentarlo. A los asociados que deseen instruirse reservadamente en sus deberes religiosos, recibir los Santos Sacramentos, o hacer canónicas sus uniones ilícitas, se les facilitará el logro de sus propósitos con toda diligencia (Archivo, fol. 22). Además, se dice que:

Nunca se debe dar el ajuar antes que nazca el niño, sino una vez bautizado, o bien para que lo lleven a la pila bautismal. Esto debe darse a los hijos de los socios antiguos y a los modernos cuando tengan tres meses de asistencia. (Archivo, fol. 23)

Llama la atención la lectura de los problemas sociales y la intención de enfrentarlos, de manera primaria y práctica, a partir de esta descripción:

La situación obrera es difícil por la carestía de la vida y escasez de trabajo; a esto se agrega la falta de educación por carecer de escuelas y techo, que los hace vivir pobremente y sin aspiraciones, pues el sueldo no alcanza ni para los más indispensables gastos. Para olvidar su triste situación beben en demasía y el problema se agudiza, pues sale a trabajar la mujer para salvar la parte financiera, lo que trae mayores complicaciones para los hijos abandonados en el hogar sin cariño y sin lumbre. (Archivo, fol. 33)

No está planteada, sin embargo, la USCO como centro de reflexión sobre las causas de la pobreza, sino como lugar de capacitación laboral básica. La confianza está puesta en que, con un trabajo mejor realizado, el obrero tendrá oportunidad de salir de la pobreza y educar mejor a sus hijos y que la 
mujer trabaje, se ve más como inconveniente que como posibilidad económica y personal favorable, por eso una mayoría de cursos está dirigido a las mujeres y sus actividades en el hogar, de ingresos auxiliares, sin intenciones profesionales. La obra, incluirá colegios para los hijos de los obreros y asociados, a partir de 1971 (Archivo, fol. 51).

Por otra parte, los voluntarios que participan en USCO tienen función transmisora de saberes básicos y alfabetización, pero no participación efectiva en la orientación de la Obra (Archivo, fol. 47). Aparecen en los archivos más los nombres de los benefactores que de los actores cotidianos de la formación y enseñanza, cuya promoción dentro de la Obra no es evidente ni considerada necesaria. Los voluntarios nunca conformarán un cuerpo decisivo ni tomarán la iniciativa de ninguna innovación o reforma.

En 1951 se iniciaron las clases para obreros y obreras, en locales cedidos por los Hermanos de la Salle y escuelas distritales. Sin embargo, relata Pilar García: "deseábamos tener una sede para el centro y los obreros nos ofrecieron trabajar, sin remuneración, los sábados por la tarde y los domingos. Fue tanta su generosidad que siendo todos pobres iniciaron una colecta que llegó a \$262” (El Espectador, 16 de mayo de 1976, 1-B). Es de resaltar que, pese a estos inconvenientes financieros, en los archivos disponibles está consignado que entre 1951 y 1962, el flujo de caja y el balance económico no muestran pérdidas.

La Institución compra un lote de tres fanegadas a la Beneficencia en 1953, con un crédito pagadero a 20 años. La firma Martínez Cárdenas hizo gratuitamente los planos de la obra y se estableció una Junta de Señoras para ayudar en la financiación bajo la coordinación de las Damas. Los ocho años de construcción, con ayuda de los mencionados obreros son resumidos así: "en el terreno se levantó un edificio, en cuyo primer piso se encuentran tres consultorios médicos y dentistería que prestan servicios gratuitos a los socios del Centro, dos salas de espera, 4 cuartos de baño; en el segundo piso están los talleres de Modistería, donde toman clases todas las tardes 120 niñas jóvenes, quienes reciben su diploma al fin del año. En 1959 se construyó un teatro al aire libre con escenario cubierto, donde se da esparcimiento a los obreros y obreras que asisten cada fin de semana y cada quince días hay un programa especial para todos los socios con sus esposas e hijos (Archivo, fol. 31).

En todo este tiempo, cabe mencionar el patrocinio de Bertha Puga de Lleras, chilena y esposa del presidente Alberto Lleras Camargo, quien asistirá a la bendición e inauguración el 16 de abril de 1961. Ese día, Monseñor Emilio de Brigard bendice las Escuelas, que prestarán sus servicios a 650 niñas. (Archivo, fols. 31 y 106). El 8 de mayo del mismo año, la Fundación Alejandro Ángel Escobar otorga a USCO el premio de Beneficencia, cuyo donativo se reservó para la construcción, a partir de 1962, de dos plantas de talleres para la capacitación de los obreros en mecánica industrial y automotriz, electricidad, radio y televisión, inglés, mecanografía, dibujo y carpintería; y se capacitarían mujeres jóvenes en alfabetización, contabilidad, corte y confección, tejidos, encuadernación, culinaria y primeros auxilios. La alfabetización se ampliará más tarde a ancianos que llegaban a esta edad sin saber leer y escribir.

El premio otorgado por la Fundación Alejandro Ángel Escobar a USCO sería el primero en una larga lista de premios y reconocimientos que incluirían la Cruz de Boyacá en 1973, la Medalla Cívica de Bogotá, el premio Ángel Escobar (1961) y la Orden de San Carlos.

\section{Servicios educativos}

Como podrá observarse en las estadísticas ordenadas en las tablas 2, 3, 4 y 5, la USCO mantuvo desde sus inicios en 1951 y hasta 1962 un esquema de funcionamiento y acciones rígidas, centra- 
do en la prestación de servicios educativos, médico-sanitarios y religiosos, a la creciente población obrera de Bogotá.

En cuanto a lo educativo, desde 1958 existió una escuela primaria con profesores que desde 1961 dependían del municipio y luego de la Secretaría de Educación del Distrito, a la cual no se cobró alquiler alguno, hasta la extinción de la escuela misma en el 2008. La escuela fue siempre gratuita y en su ocupación más alta albergó a 550 alumnas.

En 1971 se crea el Colegio Cooperativo, como una prolongación de la obra educativa ante el crecimiento en edad de las niñas de los primeros afiliados a la Obra. $\mathrm{Al}$ Colegio Cooperativo fueron asignados 10 profesores del Distrito y los gastos administrativos quedarían a cargo de USCO. Dentro de la intuición originaria del Centro Obrero y sus modos típicos de obrar, la creación de una cooperativa representó una novedad, si bien sus miembros tampoco tuvieron voz ni voto en la dirección global del Colegio. El promedio de alumnas llegó a 400 . La institución cerró sus puertas en el 2013.

Aparte de esta modalidad educativa, durante algunos años el Centro Obrero pidió al SENA cooperación para la capacitación de obreros, en cursos diurnos y nocturnos, pero el convenio cesó hacia 1978, sin registros de las razones. Esto afectó la inserción de la USCO en procesos de formación técnicos actualizados y acordes con las transformaciones del mundo laboral en Bogotá.
Tabla 2. Servicios educativos USCO 1951-1962

\begin{tabular}{|c|c|c|c|}
\hline \multirow[b]{2}{*}{ Año } & \multicolumn{3}{|c|}{ servicios educativos } \\
\hline & $\begin{array}{c}\text { Matriculados/ } \\
\text { inscritos }\end{array}$ & $\begin{array}{c}\text { Visitas a } \\
\text { hogares de } \\
\text { obreros }\end{array}$ & $\begin{array}{c}\text { Niñas } \\
\text { en escuelas }\end{array}$ \\
\hline 1951 & 2.223 & 6.796 & \\
\hline $\begin{array}{l}1953 \\
111\end{array}$ & $2.694(2)$ & 5.588 & \\
\hline 1954 & & 5.005 & \\
\hline 1955 & & 4.607 & \\
\hline 1956 & & 3.242 & \\
\hline 1957 & 2.923 & 4.381 & 150 \\
\hline 1958 & $\begin{array}{l}1.600(3) \\
1.107(4) \\
\end{array}$ & & \\
\hline 1960 & & & \\
\hline 1962 & $\begin{array}{l}3.229(5) \\
4.112(6)\end{array}$ & & \\
\hline
\end{tabular}

Fuente: elaborado por el autor con base en: 1951 (Archivo, fol. 91). 1953 (Archivo, fol. 94). 1954 (Archivo, fol. 96). 1955 (Archivo, fol. 98). 1956 (Archivo, fol. 101). 1957 (Archivo, fol. 103). 1958 (Archivo, fol. 109). 1960 (Archivo, fol. 105). 1962 (Archivo, folios $115-118$ ).

\section{Notas}

(1) Este año registra la donación, por parte de Manuel Antonio Cuéllar y su esposa, de la casa para la naciente comunidad. Esta casa sigue perteneciendo a la Asociación de damas Unión Social.

(2) Socios

(3) Mujeres

(4) Obreros

(5) Número inicial de personal en centros, escuelas y talleres

(6) Número final de personal en centros, escuelas y talleres 


\section{Servicios médicos}

Pasando a los servicios médicos, desde su fundación, los consultorios hicieron parte de la obra, como elemento propio de USCO, pues la Obra Sopeña no los contemplaba en principio (Fernández, 1993, pp.109-114). La organización básica corresponde a la forma de un dispensario: para que esté bien atendido, debe haber en cada consulta un médico y dos enfermeras. Por lo mismo, de víspera hay que asegurar la asistencia para buscar remplazo en caso de ausencia. Los enfermos deben llevar su carnet con la fecha y médico que les atiende y recibir el número según lleguen para la consulta. Este carné solo se puede dar al obrero que asiste al Centro (...) Procúrese que haya personas fijas y responsables para buscar y dar las medicinas, como también para cuidar de todo el equipo médico (Archivo, fol. 22).

Tabla 3. Servicios médicos USCO 1951-1962

\begin{tabular}{|c|c|c|c|c|}
\hline \multirow{2}{*}{ Año } & \multicolumn{4}{|c|}{ servicios médicos } \\
\hline & $\begin{array}{l}\text { Enfermos } \\
\text { atendidos }\end{array}$ & $\begin{array}{c}\text { Entrega de } \\
\text { medicamentos }\end{array}$ & $\begin{array}{l}\text { Aplicación de } \\
\text { inyecciones }\end{array}$ & Dentistería \\
\hline \multicolumn{5}{|l|}{1951} \\
\hline \multicolumn{5}{|l|}{1953} \\
\hline 1954 & 4.157 & $\begin{array}{c}6.355 \\
\text { unidades }\end{array}$ & 5.631 & \\
\hline 1955 & 3.274 & $\begin{array}{c}5.347 \\
\text { unidades }\end{array}$ & 5.206 & \\
\hline \multicolumn{5}{|l|}{1956} \\
\hline \multicolumn{5}{|l|}{1957} \\
\hline 1958 & 3.059 & 4.900 & 1.925 & $\begin{array}{c}430 \\
\text { Extracciones } \\
\text { y } 163 \text { calzas }\end{array}$ \\
\hline 1960 & 2.883 & 4.930 & 1.577 & \\
\hline 1962 & & & & \\
\hline
\end{tabular}

Fuente: elaborado por el autor con base en: 1951 (Archivo, fol. 91). 1953 (Archivo, fol. 94). 1954 (Archivo, fol. 96). 1955 (Archivo, fol. 98). 1956 (Archivo, fol. 101). 1957 (Archivo, fol. 103). 1958 (Archivo, fol. 109). 1960 (Archivo, fol. 105). 1962 (Archivo, folios $115-118$ ).

\section{Servicios religiosos}

La Obra nació con una intención religiosa y moralizadora, no unida a los círculos de reflexión (privilegio de algunos clérigos entusiastas de la cuestión social), sino al nivel más básico de organizaciones sociales de tipo cooperativo, solidario y de voluntariado (Bidegaín, 2004, pp. 323-341). Así mismo, la Obra no mostró interés reflexivo, sino alivio de la pobreza efectiva y recuperación del espacio perdido para la doctrina religiosa católica. La sociedad es vista por la iglesia como una estructura irreformable, en que las distancias sociales deben conservarse (De Roux, 1983, pp. 25-32).

Por ello, aunque la Iglesia en su conjunto considera que la situación de esa época es de acción, no va al fondo del fenómeno de violencia partidista y despojo masivo de tierras, se limita casi siempre a instar a los campesinos a no abandonar sus tierras para venir a pauperizar la ciudad, pero no se tienen en cuenta las terribles razones del éxodo (Mantilla, 1994, pp. 279-286).

Al tiempo con la violencia, las costumbres cambian poco a poco y hay un abuso generalizado del alcohol, lo cual conduce a un mayor empobrecimiento de las clases obreras, hecho que se asocia sin más a la ausencia de sacramentos (Cifuentes y Prieto, en Miradas, 2015, pp. 328-329). La respuesta de la iglesia por ello estuvo en buscar la moralización de las costumbres y que las gentes pobres se ocuparan sobre todo en oficios manuales, los que de paso mejorarían el sustrato material de los obreros no calificados de esta época.

Llama la atención, que la celebración de los sacramentos no fuera un proceso de evangelización y consolidación de una vida cristiana y un carácter humano más rico y formado, sino una obligación para pertenecer plenamente a la Obra, regularizar un estado de vida o recibir ocasionales beneficios, mentalidad que, lastimosamente, persiste hoy en muchas de nuestras obras sociales. 
Martín Gil Plata. Pbro.

Tabla 4. Servicios religiosos USCO 1951-1962

\begin{tabular}{|c|c|c|c|c|c|}
\hline \multirow{2}{*}{ Año } & \multicolumn{5}{|c|}{ servicios religiosos } \\
\cline { 2 - 6 } & $\begin{array}{c}\text { Matrimonios } \\
\text { legalizados }\end{array}$ & $\begin{array}{c}\text { Retiros } \\
\text { espirituales }\end{array}$ & Bautizos & $\begin{array}{c}\text { Entronizaciones } \\
\text { Sagrado Corazón }\end{array}$ & Comuniones \\
\hline 1951 & & & 223 & 275 & \\
\hline $1953(1)$ & 44 & & 254 & 237 & \\
\hline 1954 & $75(2)$ & 1.408 & 254 niños & 335 & \\
\hline 1955 & 62 & 1.713 (obreros y obreras) & 2 adultos & & 1.686 \\
\hline 1956 & $60(2)$ & $1.651(3)$ & & & 1.852 \\
\hline 1957 & $90(2)$ & $1.700(3)$ & & & Más de 500 (1) \\
\hline 1958 & $60(2)$ & & 200 & & \\
\hline 1960 & 30 & $1.442(3)$ & 210 & & \\
\hline 1962 & & & & & \\
\hline
\end{tabular}

Fuente: elaborado por el autor con base en: 1951 (Archivo, fol. 91). 1953 (Archivo, fol. 94). 1954 (Archivo, fol. 96). 1955 (Archivo, fol. 98). 1956 (Archivo, fol. 101). 1957 (Archivo, fol. 103). 1958 (Archivo, fol. 109). 1960 (Archivo, fol. 105). 1962 (Archivo, folios 115 - 118 ).

\section{Notas}
(1) Niños para el catecismo
(2) Sin precisar
(3) Ejercicios

Tabla 5. Otros servicios USCO 1951-1962

\begin{tabular}{|c|c|c|c|c|}
\hline \multirow{2}{*}{ Año } & \multicolumn{2}{|c|}{ otros servicios } & \multicolumn{2}{c|}{ Entronizaciones Sagrado Corazón } \\
\cline { 2 - 5 } & $\begin{array}{c}\text { Ajuares } \\
\text { entregados }\end{array}$ & Retiros espirituales & Bautizos & \\
\hline 1951 & 250 & 250 & 2.250 & \\
\hline $1953(1)$ & & & & \\
\hline 1954 & & & & \\
\hline 1955 & & & & \\
\hline 1956 & & & & \\
\hline 1957 & & & & \\
\hline 1958 & & & & \\
\hline 1960 & & & & \\
\hline 1962 & & & & \\
\hline
\end{tabular}

Fuente: eFuente: elaborado por el autor con base en: 1951 (Archivo, fol. 91). 1953 (Archivo, fol. 94). 1954 (Archivo, fol. 96 ). 1955 (Archivo, fol. 98). 1956 (Archivo, fol. 101). 1957 (Archivo, fol. 103). 1958 (Archivo, fol. 109). 1960 (Archivo, fol. 105). 1962 (Archivo, folios $115-118$ ).

\section{Notas}

(1) Juguetes entregados en las familias y en el catecismo

(2) Paseo a Villeta

(3) Paseo a Zipaquirá 


\section{Conclusiones}

La obra de la Unión Social Centro Obrero USCO, se insertó completamente en la Acción Católica para Colombia, según la orientación de la Conferencia Episcopal presidida por Monseñor Ismael Perdomo, tanto en sus intenciones sociales, derivadas de la respuesta a la angustiosa situación de miseria de campesinos y obreros, como de reacción frente al avance de las asociaciones de corte socialista y comunista surgidas en tales ambientes. El esquema básico de atención y actividades es común a las instituciones nacidas en esta época y sigue una línea descendente, en que los beneficios de un conglomerado social son eventualmente compartidos, tanto en especie como en conocimientos, con otro estrato inferior en oportunidades y nivel formativo.

La USCO no nació como una entidad original con intuición propia, sino como derivación de las Damas Catequistas, que continuarán su trabajo como Obra Cultural y Social Sopeña, vigente en la actualidad. El nacimiento de USCO es posible por la separación de dos miembros de la obra original que modifican los horarios, pero no la intención inicial. El paso de una obra a otra no tuvo ninguna mediación ni una diferenciación suficiente que le diera identidad en torno a un proyecto común de rasgos propios. Esto quizá ocasionó que, a lo largo de los años, no hubiera ingreso de miembros efectivos a la dirección de la Obra.

De hecho, nunca hubo un cuerpo directivo, sino una estructura simple y vertical que daba toda autoridad a las fundadoras y reconocía primariamente la función de los benefactores. No consta nunca, que los voluntarios participaran a modo de consejo en algún tipo de evaluación de las actividades. Dentro de la lógica de la Obra, los obreros solo participan como receptores y beneficiarios.

Llama la atención el carácter solitario de la Obra de Unión Social. No hay vínculos más allá de la jerarquía eclesiástica y algunos generosos patrocinadores. En ninguna parte, para este periodo, se menciona una interacción con comunidades religiosas ni con otros programas de atención social o formación. Da la impresión de una Obra que quiere ser autosuficiente y aislada desde el comienzo, con una forma de obra repetitiva y cerrada, sin grandes posibilidades de revisión o adaptación, como si su forma primera revistiera una convicción invariada de respuesta a los problemas sociales, a pesar de la evolución de estos durante toda una década.

\section{Referencias}

Bidegaín, A. (2004). Historia del cristianismo en Colombia: corrientes y diversidad. Bogotá: Taurus.

Cehila. (1981). Historia general de la Iglesia en América Latina, volumen VII, Colombia y Venezuela. Salamanca: Sígueme.

El Espectador. Un milagro de 25 años. (16 de mayo de 1976), 1-B.

Fernández, A., Fernández, S. (1995). Vida y Obra de Dolores R. Sopeña. Madrid: BAC Popular.

Gil, Martín (2016). Vida del Siervo de Dios Ismael Perdomo. Bogotá: Arquidiócesis de Bogotá.

Londoño, P. (2004). Religión, cultura y sociedad en Colombia. Bogotá: Fondo de Cultura Económica.

Mancera, J., Alzate, C., Benavides, F. (2015). Arquidiócesis de Bogotá, 450 años: Miradas sobre su historia. Bogotá: USTA y Curia Arzobispal.

Mantilla, L. (1994). Historia de la Arquidiócesis de Bogotá. Su itinerario evangelizador 15641993. Bogotá: Arquidiócesis de Bogotá. 
Restrepo, F. (1951). Colombia en la encrucijada. Bogotá: Biblioteca Popular de Cultura Colombiana.

Revista La Iglesia. (1945). Órgano Oficial de la Arquidiócesis de Bogotá, Año XXXIX, (89), Bogotá: Tipografía América.

Roux de, R. (1993). Una Iglesia en estado de alerta.
Funciones sociales y funcionamiento del catolicismo colombiano. 1930-1980. Bogotá: Servicio Colombiano de Comunicación Social.

Unión Social Centro Obrero. Archivo General. 191 folios, sin editar. Documentos fundacionales y correspondencia en original.

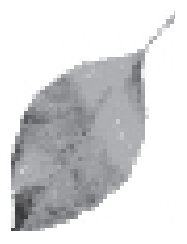

